\title{
Snhaltzäiberficht.
}

\section{Teil. Rontursotoronug.}

Erite 8 u

Selte

1. Titel. MUlgemeine $\mathfrak{B e f t i m m u n g e n .} \quad \$ \S 1$ bis 16 . . . 3

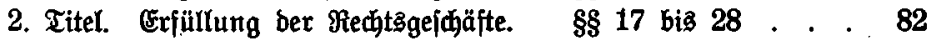

3. Titel. Infechtung. $\quad \$ \$ 29$ bis 42 . . . 123

4. Titel. $\mathscr{A}$ usfontberung. $\quad \$ \$ 43$ bia 46 . . . 179

5. Titel. भKbfonderung. $\quad-\$ \S 47$ bi 52 . . . 197

6. Titel. Uufrechnung. $\quad \$ \$ 53$ biz 56 . . . 219

7. Titel. Mafígläıtbiger. $\quad \$ \$ 57$ bis 60 . . 235

8. Titel. ^onfurżläubiger. $\quad \$ \$ 61$ bis 70 . . . 248

8weites Bud. Monturguerjahren.

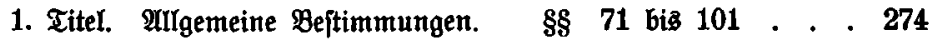

2. Titel. Cröffnungäberfahren. $\quad \$ \$ 102$ bis 116 . . . 308

3. Titel. Teilungsmmafíe. $\quad \$ 8117$ bis 137 . . 329

4. Titel. Shuldenmaffe. $\quad \$ \S 138$ bis 148 . . 353

5. Titel. Berteilung. $\quad \$ \$ 149$ bis 172 . . . 373

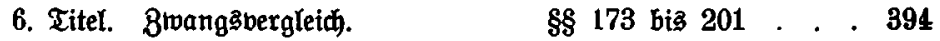

7. Titel. Einfteflung bea Berfahrens. $\quad \$ \$ 202$ bis 206 . . . 426

8. Titel. Bejonbere Beftimmungen. $\quad \S \S 207$ bis 238 . . . 430 ,

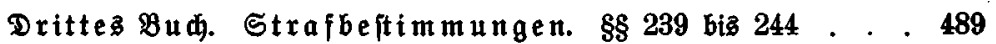

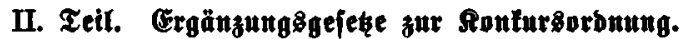

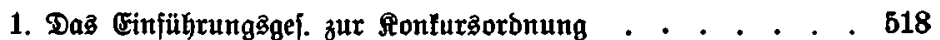

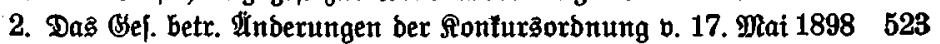

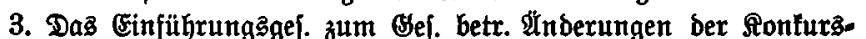
orbnung vom 17. Mai 1898 . . . . . . . . . . . . 624

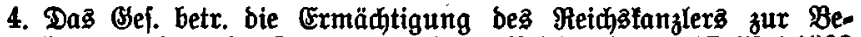
fanntmađung ber Texte veridiebener Reidşgefełe v. 17. Mai 1898528

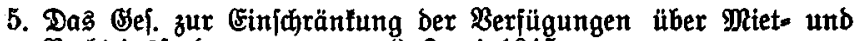
Badtzinsforberungen bom 8. Juni 1915 . . . . . . . . 528

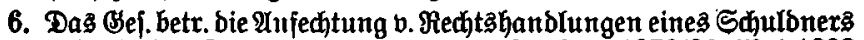

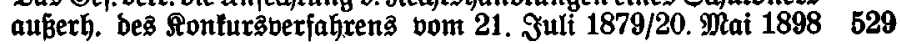




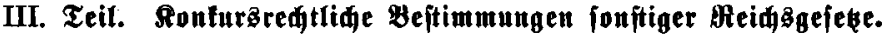

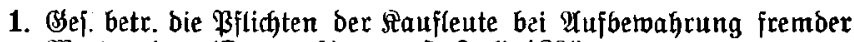
Wertpapiere (Depotgef) vom 5. Juli 1896 . . . . . . . 534

2. Gej. betr. bie Ermerbz= und Wirtjhajtżgenvijenidajten i. ठ. F. vom 20. Mai 1898 . . . . . . . . . . . . . . . . 537

3. Bei. betr. bie Bejellichaften mit bejdräntter Saftunt i. o. F. bom 20. Mai 1898 . . . . . . 549

4. Şypothetenbantgef. vom 13. Эuli 1899 . . . . . . . . . 551

5. Bej. betr. bie gemeinfamen Rechte ber Bejizer von Shuld= veridhreibungen vom 4. Dezember $1899 . \quad$. . . . . . . . 553

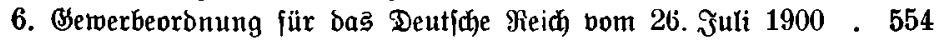

7. Bej. über bie privaten Berjidherungäunternehmungen vom 12. Mai 1901 . . . . . . . 556

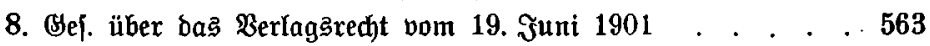

9. Sdjecfigej. vom 11. Mäñ 1908 . . . . . . . . . . . . 565

10. Bef. über ben Berfiderungsbertrag vom 30. Mai 1908 . . 566

11. (Kej. über bie Sid)erung Der Bauforberungen bom 1. Juni 1909568

Mnhang: Bergleidjenbe Bujammenjtelluntg ber ßaragraphen ber alten und ber nummehrigent Faffung ber Ronfursoronung . . . . 571

Sadhregifter nach ber Budbitabenfolge . . . . . . . . . . . . 575 